\title{
Prospective Evaluation of Spent Sulfuric Acid Recovery by Process Simulation
}

\author{
Krisztina Várnai ${ }^{*}$, László Petri², Lajos Nagy \\ 1 Department of Process Engineering, Faculty of Engineering, University of Pannonia, 10 Egyetem str., H-8200 Veszprém, Hungary \\ ${ }^{2}$ Medicinal Chemistry Research Group, Research Centre for Natural Sciences, 2 Magyar Tudósok krt., H-1117 Budapest, Hungary \\ * Corresponding author, e-mail: varnaik@fmt.uni-pannon.hu
}

Received: 05 February 2020, Accepted: 08 June 2020, Published online: 12 October 2020

\begin{abstract}
This study presents the steady-state simulation and optimization with regard to the recovery of spent sulfuric acid. Our purpose was to prove the utility of process simulation in terms of designing with special materials using energy-efficient methods. Process simulation is used in order to compare technological variants, analyze technological problems that occur as well as optimize the process. In this investigation three concentration processes are compared: azeotropic distillation and multiple-effect evaporation both in co-current and counter-current modes. The main aspects of the comparison are energy consumption and heat efficiency. Process simulation is an adequate tool for analyzing the thermal decomposition of sulfuric acid, the presence of sulfuric acid in the vapor fraction, and the costs of applying a third agent. Here, three models and a simulation-based prospective evaluation of energy consumption and the economy are presented. It is shown that the process of azeotropic distillation consumes an extremely large amount of thermal energy which seems to be more than that consumed by single-effect evaporation, while triple-effect evaporation in the countercurrent mode was found to be the most thermally efficacious.
\end{abstract}

\section{Keywords}

sulfuric acid, distillation, azeotropic distillation, multi-effect evaporation, process simulation, recovery, cost effectiveness

This article was originally published with an error. This version has been corrected/amended in the Corrigendum. Please see the Corrigendum (https://doi.org/10.3311/PPch.18012)!

\section{Introduction}

Nowadays, excess quantities of industrial waste acid have become not only a serious threat to environment but also a huge resource waste. Sulfuric acid is widely used in chemical industry, majorly in the petrochemical, steel, fertilizer, detergent, dyestuff and pharmaceutical industries. There are some known technologies to remove impurities from contaminated sulfuric acid and recover it, however most of the recently published works are mainly focusing on recovery of valuable metal components [1-4]. To recover and recycle the sulfuric acid is more challenging, thus, very limited improvements have been achieved. The most applied techniques, such as the MECS ${ }^{\circledR}$ Wet Gas $\left(\right.$ SULFOX $^{\mathrm{TM}}$ ) Technology [5], are based on old inventions related to combustion or high-temperature treatment of the contaminated wastewater [6-8]. Recently, as sustainable development is becoming more-and-more important part of our scientific and everyday life, both, there is a need for mild wastewater treatment, which avoids the disadvantages of the combustion of the corrosive spent sulfuric acid at high temperature, the purification and oxidation of $\mathrm{SO}_{2}$ at high temperature. For instance, a low carbon footprint process has been patented recently for recovery and regeneration of sulfuric acid from the spent sulfuric add catalyst of the alkylation of olefins and alkanes by using a hydrophobic supported liquid membrane [9]. In addition, few membrane-based approach were also published, recently $[10,11]$. One can conclude, we have a lack of novel sulfuric acid recovery technologies which could be applicable for large-scale industrial processes. In our research, we have chosen and analyzed three commonly used technical variants of distinct sulfuric acid recovery methods via process modelling. Additionally, a sensitivity examination under different pressures was performed. Our process simulation can be used for upcoming plantwide control since it is capable of optimizing process control. The simulator model has been designed to acquire further efficiency aspects, e.g. energy-efficiency, economic efficiency, etc., in order to help choose the technical variant's field to be included during optimal operation. 
Chemical plants often include separation technology subunits to recover products and by-products. This is mainly accomplished by multistage processes that involve distillation or evaporation [12]. In this publication, azeotropic distillation, single-effect evaporation, co-current multiple-effect evaporation and counter-current multiple-effect evaporation were compared as possible processes for the recovery of diluted sulfuric acid. However, numbers of simulation based description of evaporation systems has been published recently [13-16], only one work included sulfuric acid recovery [17]. This further emphasizes the urgent need for improvements in modelling of spent acid regeneration via separation technologies.

A multiple-effect evaporator can be operated in three modes: the co-current, the counter-current and the mixedflow mode, in which the flows of steam or vapor and the solution are parallel in some vessels and anti-parallel in others [18]. The counter-current mode results in the highest steam economy, which is generally defined as the mass ratio of the amount of vapor evaporated from the solution to the amount of steam that enters the evaporator. Although the co-current mode results in a lower steam economy, it has relevant advantages:

1. low temperature in the last-effect vessel, which minimizes degradation losses, and

2. favorable pressure profile of the solution, which allows it to flow through the evaporator without the need for pumping $[19,20]$.

There are mathematical models of distinct MultipleEffect Evaporation (MEE) systems [15, 21, 22], such as the parallel/cross, forward and backward feed configurations. According to the research the parallel/cross feed configuration exhibits better performance characteristics than the other two feed configurations [23]. The parallel/cross feed configuration has a higher gained output ratio and lower specific heat consumption than the other two arrangements.

\section{Methods}

In this paper, some process simulation models for concentrating industrial spent sulfuric acid are presented. To obtain cost- and energy-effective industrial process, the spent sulfuric acid has to be regenerated. Three main issues were considered for the process simulation. In particular: the costand energy-effectiveness, which is always desired for industrial processes, the vapor-liquid equilibrium of the sulfuric acid solution, and finally the thermal stability issue, which is related to the possible (re)generation of $\mathrm{SO}_{2}$.

\subsection{Energy and economical approach}

Regeneration technology has to be energetically and economically efficient. Most process simulator programs can calculate costs and energy consumption, which is a basis for the design of a plant. Our purpose was to compare the energy consumption of three operations with the same specifications $(20 \% \mathrm{w} / \mathrm{w}$ sulfuric acid should be concentrated to $68 \% \mathrm{w} / \mathrm{w}$ ) by applying optimum operational parameters (based on process modelling). On the other hand, the cost-effectiveness was analyzed. The cost parameters of Medium Pressure (MP) and High Pressure (HP) steam were inserted in the Aspen process simulation program. Both could be used to simulate direct evaporation. The concentration of acid solution at the outlet was kept constant at $61 \% \mathrm{w} / \mathrm{w}$, since in the case of MP steam no higher outlet concentration could be achieved.

\subsection{Chemical simulation}

During the concentration of the sulfuric acid solution, sulfuric acid can appear in the vapor phase. The vapor-liquid equilibrium of the sulfuric acid solution is shown in Fig. 1. Process simulation was used to predict the amount of sulfuric acid in the vapor stream. Fig. 1 adumbrates that sulfuric acid in the vapor phase is not critical, but our purpose was to prove this assumption via process simulation. It also follows that the separation of sulfuric acid and water does not require distillation, only evaporation.

In the case of azeotropic distillation, a third agent was added to generate a new, heterogeneous azeotrope with a lower boiling point $[17,24]$. According to Fig. 2 a considerable amount of cyclohexane is needed to achieve the minimum boiling point. Our purpose was to determine how much cyclohexane is needed to be fed into the distillation column and recirculated in order that the process can continue and is worthwhile operating. This technology was described in the literature [17]; thus, it has been included

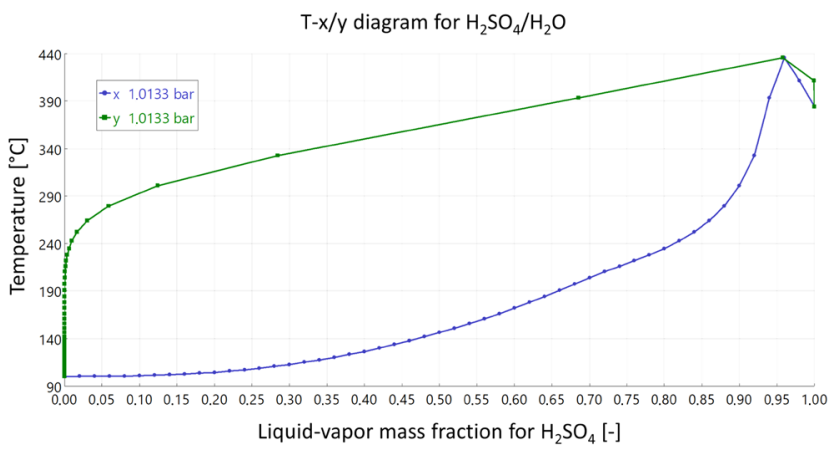

Fig. 1 Sulfuric acid-water vapor-liquid equilibrium diagram. 


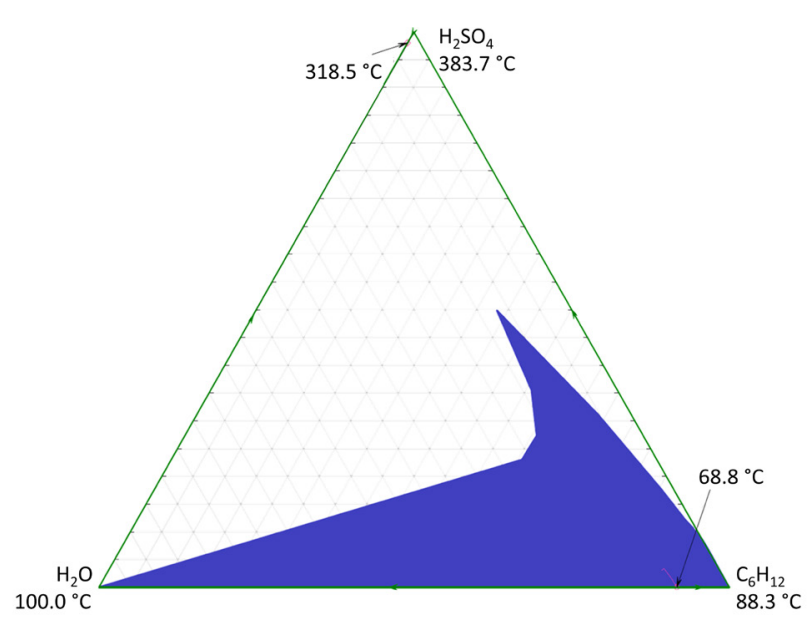

Fig. 2 Ternary plot of the azeotropic mixture (sulfuric acid-watercyclohexane). The axes depict the mass fractions.

in the scope of this study. It is shown on Fig. 2 that a large amount of cyclohexane should be introduced. This was tested using a simulation.

The azeotropic mixture deviation from Raoult's law can be described by Eq. (1):

$K_{i}=\frac{x_{i}}{y_{i}}=\frac{\gamma_{i}^{L} \times f_{i}^{L}}{\varphi_{i}^{V} \times P}$,

where $y_{i}$ and $x_{i}$ are the mole fractions of species $i$ in the vapor and liquid phases, respectively, at equilibrium. The degree of nonideality is expressed by the activity coefficient $\gamma_{i}^{L}$ in the liquid phase and the fugacity coefficient $\varphi_{i}^{V}$ in the vapor phase; $f_{i}^{L}$ denotes the pure-liquid fugacity of species $i$ and $P$ represents the total pressure of the vapor phase.

\subsection{Thermal stability}

The considerable advantage of azeotropic distillation is the reduced boiling point at which the technology can operate. This is sorely beneficial as sulfuric acid may decompose at high temperatures (around $400{ }^{\circ} \mathrm{C}$ ) into $\mathrm{H}_{2} \mathrm{O}$ and $\mathrm{SO}_{3}$ according to the Eq. (2) $[17,25]$ :

$$
\mathrm{H}_{2} \mathrm{SO}_{4(\mathrm{~g})}=\mathrm{H}_{2} \mathrm{O}_{(\mathrm{g})}+\mathrm{SO}_{3(\mathrm{~g})} ; \quad \Delta \mathrm{H}_{298}^{0}=97.5 \frac{\mathrm{kJ}}{\mathrm{mol}} \text {. }
$$

As at high temperatures spontaneous decomposition could become an issue, possible degradation should be considered. The decomposition of 1 mole $95 \%$ w/w of sulfuric acid is shown in Fig. 3. It is evident that the degradation of sulfuric acid is negligible below $200{ }^{\circ} \mathrm{C}$ (1 bar), according to Schwartz et al. [26]. This is probable according to Fig. 3, but whether the temperature can remain below $200{ }^{\circ} \mathrm{C}$ during evaporation will be examined. Our purpose was to verify this by simulation.

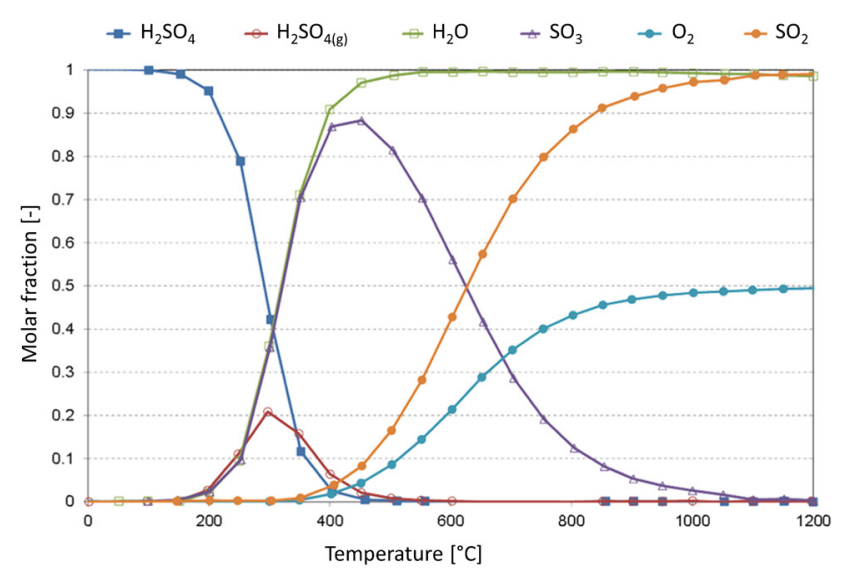

Fig. 3 Spontaneous decomposition of $\mathrm{H}_{2} \mathrm{SO}_{4}(95 \% \mathrm{w} / \mathrm{w})$ under atmospheric conditions.

\subsection{Process simulation}

The processes were analyzed using Aspen Plus v9.1. Sulfuric acid was considered to be an electrolyte solution; therefore, a thermodynamic description of dissociation is required for modeling. The embedded model methods were probed, but only e-NRTL-SR (electrolyte non-random two-liquid model with short range interactions) was able to confirm the vapor-liquid equilibrium relationship between water and the sulfuric acid solution.

\subsubsection{Simulation of azeotropic distillation}

Azeotropic distillation was examined as the first concentrating procedure. The thermodynamic model of the azeotropic distillation was based on data taken from the literature [24]. Our goal was to construct a model which is able to simulate the recovery of diluted sulfuric acid using azeotropic distillation, where cyclohexane was applied as an entrainer. To regenerate the spent sulfuric acid, the same specifications were used as earlier described by Li et al. [17]. Particularly, inlet acid stream on the column was 20 ton/h, which successfully enriched the $20 \% \mathrm{w} / \mathrm{w}$ sulfuric acid solution to $68 \% \mathrm{w} / \mathrm{w}$, while the flow rate of make-up cyclohexane was 97.5 ton/h. The flow sheet of the azeotropic distillation technology was constructed and stabilised using the equation-oriented approach. The temperature of the kettle reboiler of the column was varied and the optimum determined. To optimize the minimum power consumption, Matlab's "fmincon" function was used with the default "interior-point" algorithm. We have established a Matlab-Excel-Aspen connection, the Matlab "actxserver" function creates a local OLE Automation server that can communicate with Excel. The connection between Excel and Aspen was made using the Aspen 
Simulation Workbook. The concentration of the spent sulfuric acid at the inlet was $20 \% \mathrm{w} / \mathrm{w}$, which had to be enriched to $68 \% \mathrm{w} / \mathrm{w}$. The temperature of the inlet stream was $25^{\circ} \mathrm{C}$ under 1 bar of pressure. The cyclohexane circle included the column, heat exchanger and decanter.

The column has 4 theoretical trays. Cyclohexane is introduced in the first stage and the spent sulfuric acid stream in the second. During the optimization the composition of the distillate was tracked to avoid degradation of the concentrated sulfuric acid. Some parameters influence the quantity of the outlet streams, e.g. the temperature of the kettle reboiler, the duty of the flash separator as well as the temperature and pressure of the decanter. These parameters were optimised to achieve an adequate concentration of sulfuric acid. Briefly, the temperature of the kettle reboiler - practically the outlet temperature of the enriched sulfuric acid - is $203^{\circ} \mathrm{C}$, the duty of the flash separator was set for $22 \mathrm{MW}$, while the temperature and the pressure of the decanter was $60^{\circ} \mathrm{C}$ and $1.20 \mathrm{bar}$, respectively.

The schema of the flow sheet of the simulated distillation process is shown in Fig. 4, while the detailed stream results are provided in the Supplement Table S1. The spent sulfuric acid stream at the inlet enters via a flash separator, in which a stream of water leaves the apparatus, so the spent sulfuric acid is concentrated. The stream at the outlet is led into the column. The concentrated sulfuric acid leaves the process in the bottom stream and the distillate is led into a decanter to recover the cyclohexane. The wasted cyclohexane is made up. Fig. 2 shows that the sulfuric acid should have been enriched to achieve an immiscible mixture. This confirms the necessity of the apparatus (FLASH1) dedicated for preconcentration step. The MAKEUP stream was calculated via a mass balance using a Fortran program to avoid iteration problems and obtain a stable simulation.

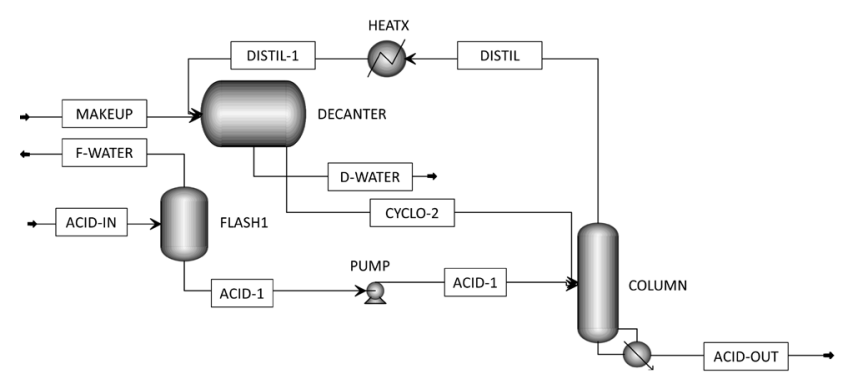

Fig. 4 Flow sheet of the azeotropic distillation process to concentrate spent sulfuric acid.

\subsubsection{Simulation of multi-effect evaporator}

The single-stage evaporation solution was analyzed as a benchmark, but many articles in the literature recommend multi-stage evaporators as a result of economic considerations $[15,27]$. The multiple-effect evaporator system was prepared according to the proposal by DeDietrich Process Systems [28], where a three-stage multiple-effect evaporator using a counter-current flow is suggested. for enriching spent sulfuric acid from $20 \% \mathrm{w} / \mathrm{w}$ to $70 \% \mathrm{w} / \mathrm{w}$.

The heating stream is introduced into the triple-effect evaporator. Secondary steam evaporated from the triple-effect evaporator is introduced into the double-effect evaporator as heating steam, and the third stream is evaporated from the double-effect evaporator and introduced into the first stage. One effect is modelled by a heat exchanger as well as a flash tank. The flow sheet is presented in Fig. 5 a), and the detailed stream results are provided in the Supplement Table S2. As a comparison, the same technology was constructed in the co-current flow, while the streams had the same properties. The schema of the flow sheet is shown in Fig. 5 b), while the stream results are provided in the Supplement Table S3. In the counter-current evaporation process a $20 \% \mathrm{w} / \mathrm{w}$ spent sulfuric acid stream at $25{ }^{\circ} \mathrm{C}$ was introduced. The sulfuric acid at the outlet was enriched up to $68 \% \mathrm{w} / \mathrm{w}$. Triple-effect evaporation was used, and the hot stream introduced in the last stage. The parameters of the High Pressure steam were the following: the pressure was 15 bar and vapor fraction 1 which means the existence of a dew point. The pressure of the stages and amount of the stream required were calculated. The co-counter evaporation process possesses the same specifications, a $20 \% \mathrm{w} / \mathrm{w}$ and $68 \% \mathrm{w} / \mathrm{w}$ sulfuric acid stream at the inlet and outlet, respectively. The stream was introduced in the first stage, and a further accessory stream before the third stage.

\subsubsection{Theoretical methodology for comparison}

A separated simulation was performed for a one-stage evaporator (Fig. 6), which then was used as a benchmark for the evaporation technologies compared in this study. We intended to set this unit to regenerate spent sulfuric acid with the same characteristics. Meanwhile performing the same enrichment, the benchmarking technology consume $24 \mathrm{MW}$ of energy. This simulated technology was then utilized as a reference to compare the investigated multiple-effect evaporation technologies. 

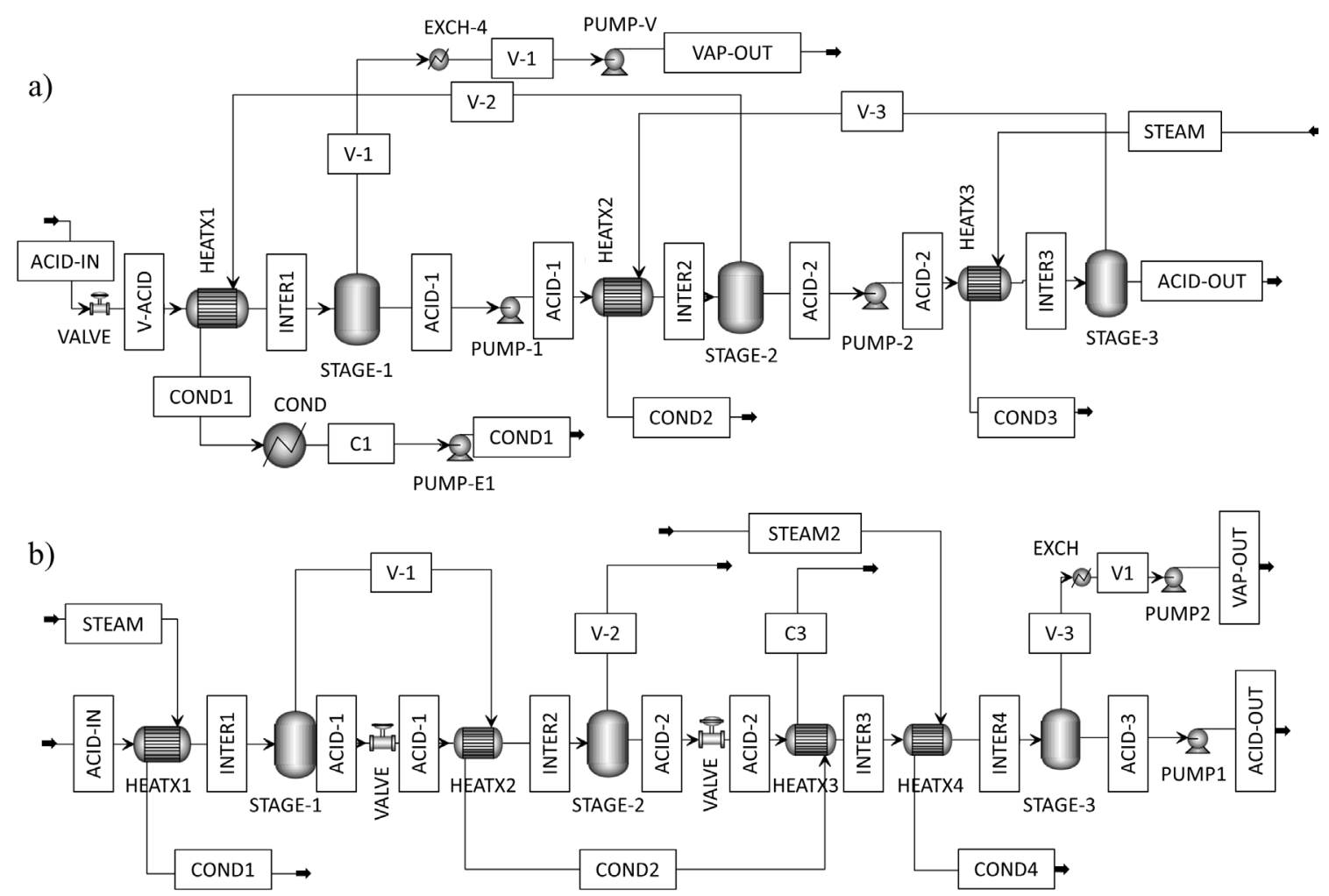

Fig. 5 Flow sheet of the multiple-effect evaporator to concentrate spent sulfuric acid in a) counter-current and b) co-current arrangement.

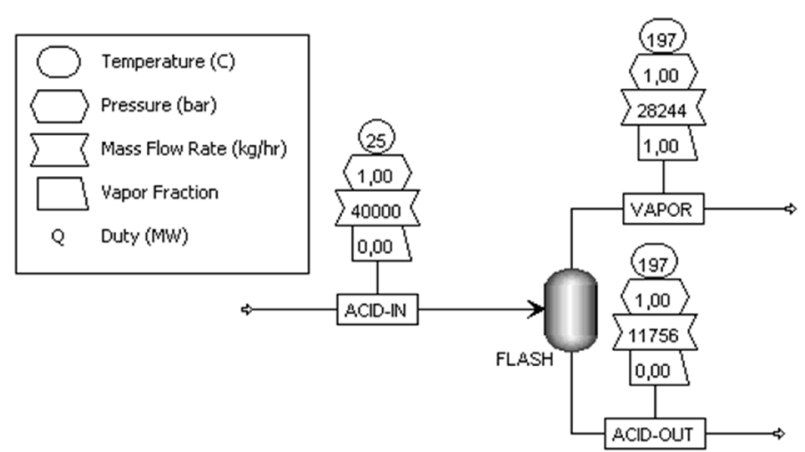

Fig. 6 Results of the single stage evaporator simulation to concentrate spent sulfuric acid.

\section{Results and discussion}

\subsection{Energy demand analysis}

The input flow rate (40 ton/h, $20 \% \mathrm{w} / \mathrm{w}$ sulfuric acid, $25^{\circ} \mathrm{C}, 1$ bar) was the same for all of the simulations, and the output stream also exhibited the same specifications $(68 \% \mathrm{w} / \mathrm{w})$. The azeotropic distillation process, in addition to the co-current and counter-current triple-effect evaporation processes achieved the required concentration (68\% w/w sulfuric acid).

The spent sulfuric acid stream at the inlet was successfully enriched to $68 \% \mathrm{w} / \mathrm{w}$. In the first step 18 ton $/ \mathrm{h}$ of water was evaporated, thus the stream ACID1 was concentrated to $37 \% \mathrm{w} / \mathrm{w}$ of sulfuric acid. The spent acid was enriched up to $68 \% \mathrm{w} / \mathrm{w}$ by the column, with the help of $98 \mathrm{ton} / \mathrm{h}$ of cyclohexane. The significant amount of organic solution required resulted in an increase of the energy demand. Finally, 12 ton/h of regenerated sulfuric acid left the system at a temperature of $203{ }^{\circ} \mathrm{C}$ and pressure of 1.3 bars. The rate of recovery of the sulfuric acid was $30 \% \mathrm{w} / \mathrm{w}$. The energy consumption of $50 \mathrm{MW}$ was extremely high, however, could still be cost-effective by using low-temperature wasted energy. The decomposition of sulfuric acid was negligible at the applied temperature.

The triple-effect evaporator models produced similar results. The rate of recovery of the counter-current evaporation was $29 \% \mathrm{w} / \mathrm{w}$, as the flow rate of sulfuric acid at the outlet was 12 ton $/ \mathrm{h}$. The sulfuric acid stream at the inlet $(20 \% \mathrm{w} / \mathrm{w}, 40$ ton/h) was successfully enriched up to $68 \% \mathrm{w} / \mathrm{W}$.

Two efficiency indices were analyzed, namely the energy efficiency and cost-effectiveness. The results of the energy efficiency index are shown in Fig. 7. As a representative and critical operation parameter, the pressure profile was analyzed at every stage, and the optimum was determined as: pressures of $0.3,0.8$ bar and 1 bar in the first, second and third stages, respectively. These specifications reduced 


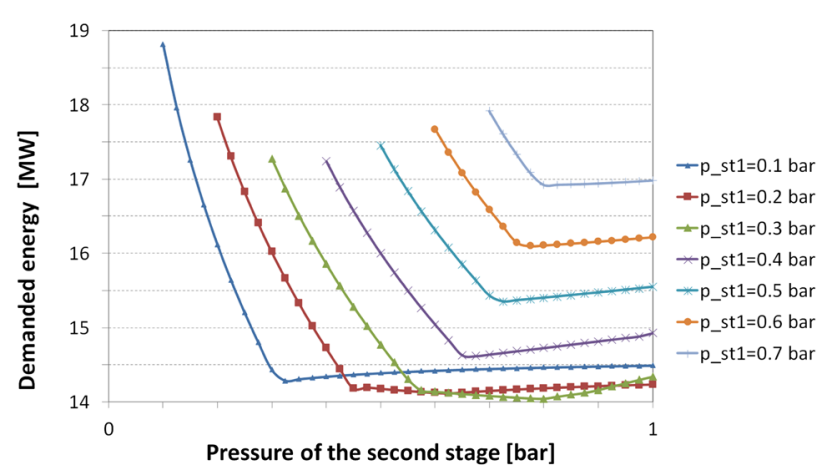

Fig. 7 Optimization of the pressure: energy demand as a function of the operating pressure.

the heat duty of the technique to $14 \mathrm{MW}$. The diagram shows the energy demand as a function of the pressure in the first and second stages (Fig. 7). All cases ran down in a similar fashion. As the pressure during the first stage increases, the minimum of the energy required is located at an ever-rising pressure during the second stage.

\subsection{Cost effectiveness analysis}

The results of the cost-effectiveness index are shown in Figs. 8 and 9. The diagrams show the total utility cost of the plant as a function of the pressure at each stage. Fig. 8 presents when Medium Pressure (MP) steam is used for direct evaporation in the third stage. Fig. 9 represents the usage of High Pressure (HP) steam using the same specifications. A concentration of up to $61 \% \mathrm{w} / \mathrm{w}$ of sulfuric acid solution could be achieved by MP as well as HP steams, however, the total utility cost of the MP steam seemed to be more cost-effective. During the third stage a pressure of 1 bar was applied, where direct steam was consumed. The total utility cost decreased as the pressure of the second stage increased. Beyond a certain threshold, the total utility cost was almost constant. This threshold

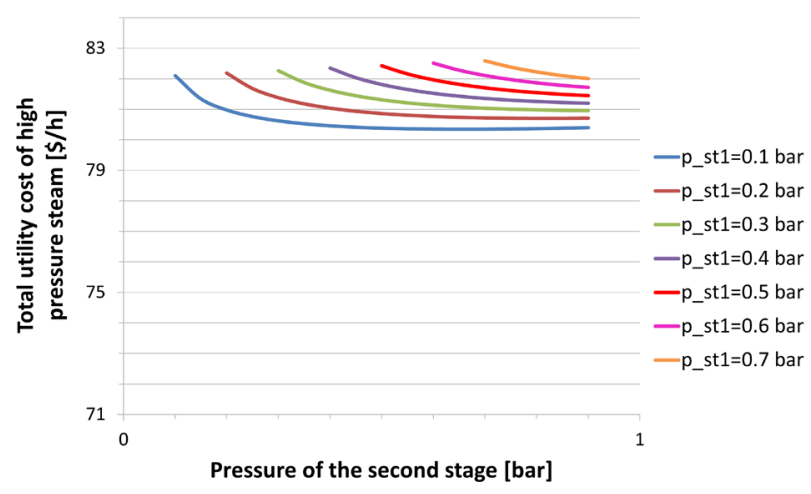

Fig. 8 Optimization of the pressure. Total utility cost when Medium Pressure steam was applied as a function of the operating pressure.

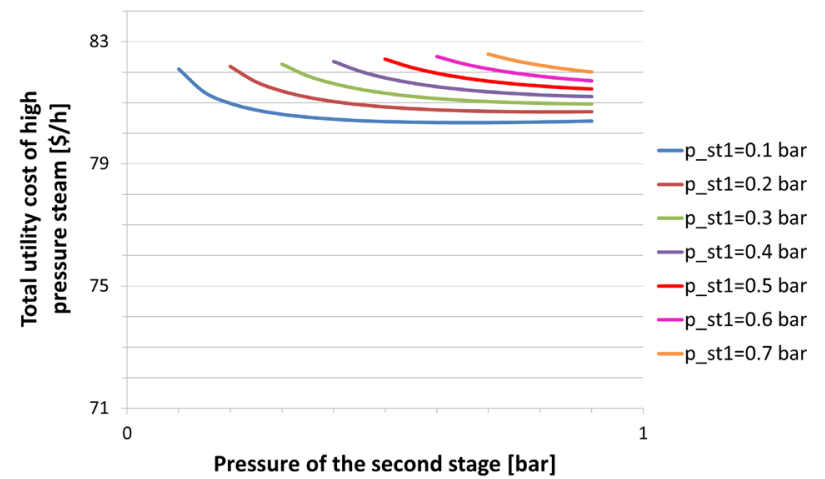

Fig. 9 Optimization of the pressure. Total utility cost when High Pressure steam was applied as a function of the operating pressure.

was 71-73 \$/h applying MP and 80-82 \$/h applying HP. The optimum range when MP steam was applied was $0.1,0.3-0.8$ and 1 bar at stages 1,2 and 3, respectively. The total utility cost was much less dependent on pressure when HP steam was applied. The optimum working range when HP steam was applied was $0.1,0.5-0.8$ and 1 bar at stages 1, 2 and 3, respectively.

The first and second steps resulted in sulfuric acid flow rates and concentrations of 33 ton $/ \mathrm{h}$ and $24 \% \mathrm{w} / \mathrm{w}$, and 23 ton $/ \mathrm{h}$ and $35 \% \mathrm{w} / \mathrm{w}$, respectively. The first and second stages were heated by the vapor of the following stage. The flow rates of the vapor streams were similar. The temperature of the acid stream at the outlet was $197{ }^{\circ} \mathrm{C}$ and the decomposition of sulfuric acid was negligible at this temperature.

The co-current mode of the triple-effect evaporator produces a sulfuric acid recovery rate of $29 \% \mathrm{w} / \mathrm{w}$, while the flow rate of the sulfuric acid stream at the outlet was 12 ton/h. Thus, recovery using this arrangement is just as effective as when the counter-current mode was applied. The heat duty of the optimum arrangement was $21 \mathrm{MW}$. The most concentrated sulfuric acid stream was introduced into the third stage, which was subject to the strongest vacuum. As a result, the temperature of the outlet stream was the lowest $\left(134{ }^{\circ} \mathrm{C}\right)$, therefore, the main advantage of this arrangement was that decomposition could be entirely avoided. On the other hand, the introduction of a secondary stream was necessary due to the reduction in motive power as the pressure decreased. High Pressure steam $\left(200{ }^{\circ} \mathrm{C}\right.$, 15 bars) was introduced into the first (STEAM) and third stages (STEAM2). The mass flow rates of STEAM and STEAM2 were 18 and 10 ton/h, respectively. The first stage and at the output of the second stage resulted in sulfuric acid flow rates and concentrations of 30 ton $/ \mathrm{h}$ and $27 \% \mathrm{w} / \mathrm{w}$, and 19 ton/h and $42 \% \mathrm{w} / \mathrm{w}$, respectively. The second stage was heated by the vapor of the previous stage. 
The energy consumption of the single-stage evaporator was $24 \mathrm{MW}$, while the process produced a recovered sulfuric acid stream with a flow rate of 12 ton $/ \mathrm{h}$ and concentration of $68 \% \mathrm{w} / \mathrm{w}$ at a temperature of $197^{\circ} \mathrm{C}$.

\section{Conclusion}

The main aim of this research was to construct process simulation models, which can help optimize the sulfuric acid regeneration process. The simulation can be used for plantwide control as the optimum working points were identified. The simulation models helped to compare the efficacity of three regeneration processes. Moreover, this study can contribute to the treatment of wasted sulfuric acid which is a serious pollution to environment. Possible recovery technologies were investigated: azeotropic distillation with a column and triple-effect evaporation both in co-current and counter-current modes. After the flowsheets were successfully synthesized, the model was optimized to enrich the concentration of spent sulfuric acid at the inlet from 20 up to $68 \%$ w/w. As a comparison, three different approaches were utilized:

1. energy efficiency and cost-effectiveness,

2. sulfuric acid in a vapor fraction, and

3. outlet temperature as an indicator of the spontaneous degradation of sulfuric acid.

In terms of the energy efficiency and cost-effectiveness, the best solution was the counter-current evaporation process. The presence of sulfuric acid in the vapor fraction was calculated via process simulation and the results show that the ubiety of sulfuric acid in the vapor fraction was negligible in each process under the investigated conditions. The outlet temperature of the enriched sulfuric acid was 200, 134 and $203{ }^{\circ} \mathrm{C}$ during the counter-current evaporation process, co-current evaporation process and azeotropic distillation, respectively, according to the simulation. With the aid of process simulation, the effect of thermal decomposition was proven to be negligible during the plant design. It is noteworthy, that further research is necessary to thoroughly analyze the dependency of the decomposition of sulfuric acid on pressure.

\section{References}

[1] Su, J., Lin, X., Zheng, S., Ning, R., Lou, W., Jin, W. "Mass transport-enhanced electrodeposition for the efficient recovery of copper and selenium from sulfuric acid solution", Separation and Purification Technology, 182, pp. 160-165, 2017.

https://doi.org/10.1016/j.seppur.2017.03.056
As the enrichment was successful, no considerable amount of sulfuric acid was found in the vapor, thermal degradation was also negligible in every case, and the thermal efficiency as well as cost-effectiveness became of the utmost importance. In this respect the counter-current mode of the triple-effect evaporator clearly outperformed the other recovery technologies. The process of azeotropic distillation consumed $50 \mathrm{MW}$ of energy as a significant amount of entrainer was introduced into the process and had to be evaporated. Co-current triple-effect evaporation demanded $21 \mathrm{MW}$ of energy; therefore, secondary steam was required to lead in the third stage. However, a possible advantage of this technology is that the most concentrated sulfuric acid is evaporated under the lowest pressure, therefore, the bubble point is minimal resulting in the lowest possible outlet temperature of the enriched sulfuric acid $\left(134{ }^{\circ} \mathrm{C}\right)$. Single stage evaporation consumed $24 \mathrm{MW}$ of energy and the flow rate and concentration of the regenerated sulfuric acid was 12 ton $/ \mathrm{h}$ and $68 \% \mathrm{w} / \mathrm{w}$, respectively. The energy consumption of the triple-effect evaporator in the counter-current mode was $14 \mathrm{MW}$, which is significantly less than other recovery technologies. As the temperature of the sulfuric acid at the outlet was below $200{ }^{\circ} \mathrm{C}$, it still falls within the stable temperature window, however, more sophisticated temperature control is necessary for this technology to prevent dangerous overshoots. Furthermore, HP and MP steam were also compared according to the cost-effectiveness of counter-current evaporation. All in all, the optimum working points seemed to be $0.1,0.5-0.8$ and 1 bar at stages 1, 2 and 3, respectively.

Our study clearly revealed the main issues related to the known sulfuric acid recovery technologies and provide important results for future plant optimizations and plantwide control. Based on our prospective evaluation, the application of process simulation was proven to be able to sort out engineering-design problems in terms of the spent sulfuric acid recovery process.

\section{Acknowledgement}

This work was supported by the project GINOP-2.2.115-2017-00059 R\&D competitiveness and excellence co-operations.

[2] Yu, Q., Ning, S., Zhang, W., Wang, X., Wei, Y. "Recovery of scandium from sulfuric acid solution with a macro porous TRPO/ $\mathrm{SiO}_{2}-\mathrm{P}$ adsorbent", Hydrometallurgy, 181, pp. 74-81, 2018. https://doi.org/10.1016/j.hydromet.2018.07.025 
[3] Qifeng, W., Xiulian, R., Jingjing, G., Yongxing, C. "Recovery and separation of sulfuric acid and iron from dilute acidic sulfate effluent and waste sulfuric acid by solvent extraction and stripping", Journal of Hazardous Materials, 304, pp. 1-9, 2016. https://doi.org/10.1016/j.jhazmat.2015.10.049

[4] Li, H., Xing, S., Liu, Y., Li, F., Guo, H., Kuang, G. "Recovery of Lithium, Iron, and Phosphorus from Spent $\mathrm{LiFePO}_{4}$ Batteries Using Stoichiometric Sulfuric Acid Leaching System", ACS Sustainable Chemistry \& Engineering, 5(9), pp. 8017-8024, 2017. https://doi.org/10.1021/acssuschemeng.7b01594

[5] DuPont Industrial Biosciences "MECS ${ }^{\circledR}$ SULFOX $^{\mathrm{TM}}$ Wet Gas Sulfuric Acid Process", [online] Available at:http://cleantechnologies. dupont.com/technologies/mecs/technologiestechnologiesmecsdupont-clean-technologies-mecs-processes/mecsr-sulfoxtmwet-gas-sulfuric-acid-process/ [Accessed: 15 May 2020]

[6] Morgenthaler, J. H. "Process for the regeneration of spent sulfuric acid", Alexandria, VA, USA, US4376107A, 1981.

[7] De La Mater, G. B., Milligan, B., Air Products and Chemical, Inc. "Purification of spent sulfuric acid", Wayne, PA, USA, US3856673A, 1973.

[8] Chou, T. C., Chen, Y. L. "Recovery and regeneration of sulfuric acid", Alexandria, VA, USA, US5547655A, 1994.

[9] Chou, C. S., Chou, T. C. "Low carbon footprint process for regenerating sulfuric acid and recovering hydrocarbons from a spent sulfuric acid catalyst from an alkylation unit", Alexandria, VA, USA, US9962687B1, 2017.

[10] Yun, T., Chung, J. W., Kwak, S. Y. "Recovery of sulfuric acid aqueous solution from copper-refining sulfuric acid wastewater using nanofiltration membrane process", Journal of Environmental Management, 223, pp. 652-657, 2018. https://doi.org/10.1016/j.jenvman.2018.05.069

[11] Guo, R., Wang, B., Jia, Y., Wang, M. "Development of acid block anion exchange membrane by structure design and its possible application in waste acid recovery", Separation and Purification Technology, 186, pp. 188-196, 2017. https://doi.org/10.1016/j.seppur.2017.06.006

[12] Fair, J. R. "Distillation: whither, not whether", Chemical Engineering Research and Design, 66(4), pp. 363-370, 1988.

[13] Jin, Y., Hu, R., Wang, Y., Cui, Y., Liu, Y., Huang, Q. "The effect of Dixon rings on direct contact heat transfer performance: Comparison of counter and co-current evaporation", Applied Thermal Engineering, 117, pp. 762-772, 2017. https://doi.org/10.1016/j.applthermaleng.2017.02.054

[14] Zhou, S., Gong, L., Liu, X., Shen, S. "Mathematical modeling and performance analysis for multi-effect evaporation/multi-effect evaporation with thermal vapor compression desalination system", Applied Thermal Engineering, 159, Article Number: 113759, 2019. https://doi.org/10.1016/j.applthermaleng.2019.113759

[15] Luyben, W. L. "Dynamic simulation of multi-effect evaporators", Chemical Engineering and Processing - Process Intensification, 131, pp. 106-115, 2018. https://doi.org/10.1016/j.cep.2018.07.005

[16] Sharan, P., Bandyopadhyay, S. "Energy optimization in parallel/ cross feed multiple-effect evaporator based desalination system", Energy, 111, pp. 756-767, 2016.

https://doi.org/10.1016/j.energy.2016.05.107
[17] Li, G., Asselin, E., Li, Z. "Process Simulation of Sulfuric Acid Recovery by Azeotropic Distillation: Vapor-Liquid Equilibria and Thermodynamic Modeling", Industrial \& Engineering Chemistry Research, 53(29), pp. 11794-11804, 2014.

https://doi.org/10.1021/ie5013079

[18] Chantasiriwan, S. "Optimum surface area distribution in co-current multiple-effect evaporator", Journal of Food Engineering, 161, pp. 48-54, 2015.

https://doi.org/10.1016/j.jfoodeng.2015.03.030

[19] Bhargava, R., Khanam, S., Mohanty, B., Ray, A. K. "Selection of optimal feed flow sequence for a multiple effect evaporator system", Computers \& Chemical Engineering, 32(10), pp. 2203-2216, 2008. https://doi.org/10.1016/j.compchemeng.2007.10.012

[20] Rein, P. "Cane Sugar Engineering", Verlag Dr. Albert Bartens KG, Berlin, Germany, 2017. https://doi.org/10.36961/cse

[21] Kaya, D., Sarac, H. I. "Mathematical modeling of multiple-effect evaporators and energy economy", Energy, 32(8), pp. 1536-1542, 2007. https://doi.org/10.1016/j.energy.2006.09.002

[22] Kumar, D., Kumar, V., Singh, V. P. "Modeling and dynamic simulation of mixed feed multi-effect evaporators in paper industry", Applied Mathematical Modelling, 37(1-2), pp. 384-397, 2013. https://doi.org/10.1016/j.apm.2012.02.039

[23] Al-Mutaz, I. S., Wazeer, I. "Comparative performance evaluation of conventional multi-effect evaporation desalination processes", Applied Thermal Engineering, 73(1), pp. 1194-1203, 2014. https://doi.org/10.1016/j.applthermaleng.2014.09.025

[24] Widagdo, S., Seider, W. D. "Journal review. Azeotropic distillation", AIChE Journal, 42(1), pp. 96-130, 1996. https://doi.org/10.1002/aic.690420110

[25] Huang, C., T-Raissi, A. "Analysis of sulfur-iodine thermochemical cycle for solar hydrogen production. Part I: decomposition of sulfuric acid", Solar Energy, 78(5), pp. 632-646, 2005. https://doi.org/10.1016/j.solener.2004.01.007

[26] Schwartz, D., Gadiou, R., Brilhac, J. F., Prado, G., Martinez, G. "A Kinetic Study of the Decomposition of Spent Sulfuric Acids at High Temperature", Industrial \& Engineering Chemistry Research, 39(7), pp. 2183-2189, 2000.

https://doi.org/10.1021/ie990801e

[27] Verma, O. P., Manik, G., Mohammed, T. H. "Energy management in multi stage evaporator through a steady and dynamic state analysis", Korean Journal of Chemical Engineering, 34(10), pp. 2570-2583, 2017.

https://doi.org/10.1007/s11814-017-0180-4

[28] DeDietrich Process Systems "Recovery, Concentration and Purification of Mineral Acids: Concentration of Sulfuric Acid and its Application", [online] Available at: https://www. ddpsinc.com/de-dietrich-services/engineered-systems/recoveryconcentration-purification\#concentration-of-sulfuric-acid-andits-application-1285698140562 [Accessed: 16 May 2020] 